\title{
Study on the Religious Ritual Polyphonic Music of Tibetan Groups in Qiaoqi
}

\author{
Xia Jiang \\ College of Music \\ Sichuan Normal University \\ Chengdu, China 610000
}

\begin{abstract}
Located at the northern end of Baoxing County, Ya'an City, Sichuan Province, Qiaoqi is a fusion and transition zone of Tibet and Han ethnic culture, Tibet and Qiang ethnic culture and other ethnic cultures. It is separated from Aba and Ganzi Titibetan prefectures just by a mountain. Although they all belong to Jiarong Tibetan group, they are distinctive from each other in culture. Due to the closed natural environment and culture, Tibetan fellows in Qiaoqi living at the foot of Jiajinshan Mountain still preserve polyphony with the original "cantata" characteristics and remain intact in their religious rituals. Thus, it would be helpful to demonstrate the unique cultural phenomenon in this region by exploring the interaction between the religious rituals and its polyphony of Tibetan groups in Qiaoqi.
\end{abstract}

Keywords-Tibetan groups in Qiaoqi; polyphony; ritual music; cultural interpretation

\section{INTRODUCTION}

At the northern end of Baoxing County, Ya'an City, Sichuan Province, there is a special Tibetan community, Tibetan groups in Qiaoqi. The community is located on the eastern margin of Tibetan-Yi Corridor and the fusion and transition zone of Tibet and Han ethnic culture, Tibet and Qiang ethnic culture and other ethnic cultures. It is separated from Aba and Ganzi Titibetan prefectures just by a mountain. Although they all belong to Jiarong Tibetan group, they are distinctive from each other in culture. Qiaoqi (called "Yiji" in Tibetan language) has the meaning of high and cold mountain ridge and is also regarded as the nearest Tibetan from Han nationality. In Qing Dynasty, it was named "Jiaoji ' 遥济' Village" under the jurisdiction of the chieftain Muping. In the 17th year of the Republic of China, the title of chieftain was cancelled and Baoxing County was established. It was at that time that the place was set up as a town named Qiaoqi "硗碛" (the homophony of Yaoji in Chinese). Wherein, "硗碛" was originally read as "Qiaoqi", but it was read as "Yaoji" in local place.

\section{RELIGIOUS BELIEFS IN QIAOQI TOWN}

Religious beliefs in the town are diversified. Among them, Tibetan Buddhism dominates the beliefs of the Tibetans in Qiaoqi. There is only one temple in Qiaoqi. It is located in Jiajinshan Park and named "Qukeraojielin" in Tibetan and also often called "Yongshou Temple". It belongs to Dge-lugs-pa. The monks of Yongshou Temple mainly come from the local area. Lama dominates all aspects in daily life of Tibetans and is respected. Before the founding of the PRC, Tibetan should send one son to become a monk if there were three sons in his family and send two sons to become monks if there five sons in his family, hence the importance of Tibetan Buddhism in the local belief system.

Jiarong area was a cultural area of bonism in history. The basin of large Jinchuan County and small Jinchuan County was the hub of Bonpo's power before Qianlong period. "Because Qiaoqi belongs to Jiarong Tibetan and was related to Xiaojin County for generations and generations, it is certainly possible for this place to once believe bonism or be influenced by bonism in the history." "ॠ", the symbol of gyung-drung-bon, was displayed on most clothes of Tibetan women in Qiaoqi.

In addition to Tibetan Buddhism, there are also Taoism beliefs of the Han people in Qiaoqi Town. There is originally no local Taoist and no fixed Taoism place and organization in Qiaoqi. Most of those believing Taoism are Han People migrated here. In Qiaoqi, the influence of Taoism is far less than that of Tibetan Buddhism.

There are also two temples in the town. One is Guanyin Temple and the other one is Wangmuzhai Temple. Believers of Guanyin Temple are mainly Han women living in the town. Wangmuzhai Temple is located at the top of Jiajinshan Mountain. It is said that the temple was built by local people for and to commemorate an imperial concubine of Qianlong who followed the army to put down the rebellion of large Jinchuan County and small Jinchuan County during Qianlong period in Qing Dynasty. Judging from the names, believers and functions of those two temples, they should belong to the beliefs of Han.

In addition, there are also many local folk beliefs, such as the worship of god of mountain. In Qiaoqi, there are 5 holy mountains, namely there are 5 gods of mountains. Among those five gods, there are female god and trumpet god and also animalized (such as frog) god. Such folk beliefs not only illustrate the diversified features of gods of mountains, but

Chen Dong. The Religion on the Tibetan Border: an Investigation into the Religion of Qiaoqi Tibetan Town in Ya'an [J] Tibetan Studies, No.2, Apr., 2008. (in Chinese) 
also exemplify the fusion and mutual acceptance of Tibetan Buddhism beliefs and local folk beliefs.

Above all, the beliefs in Qiaoqi Town include Tibetan Buddhism, primitive Bonism, local folk beliefs, Taoism and other beliefs of Han. Although the the beliefs in Qiaoqi are more diversified, they do not repulse each other, but showing a co-existing and mutual inclusive relation.

\section{STUdy OF RELIGIOUS RITUAL POLYPHONY FORMS OF TIBETAN GROUPS IN QIAOQI}

Qiaoqi is a town of song and dance, not only having rich Tibetan dance, but also having its quite distinctive polyphony. In early 1990s, polyphony of Tibetan groups in Qiaoqi was discovered. At first, teacher Yao Xiaoxia introduced the polyphony to music field by virtue of several papers. However, it did not lead to an in-depth exploration on it in the academic world. It has to be said that it is a pity in research of polyphony of Tibetan groups in Qiaoqi. Therefore based on the previous studies, this paper will sort out the polyphony, explore the basic characteristics of its music form and further explore the interaction between the polyphony and its associated ecological environment and cultural environment, so as to complement previous studies and fill in the gaps left in the study of polyphony.

In such polyphony, there are three typical forms of music, such as polyphony in religious rituals, polyphony in working scene and polyphony in entertainment. The following mainly explores and analyzes Mani, the polyphony in rituals:

\section{A. Polyphony in Rituals - Mani}

"Buddha carrying" is an important ritual for Tibetan groups in Qiaoqi in the traditional "Buddha Festival" on Jan.17 of each year in lunar calendar. In Tibet, in order to welcome the rapid coming of the era of Maitreya Buddha (also known as the Future Buddha) to help sentient beings, the silver Maitreya statue of the Jokhang Temple in Lhasa will be carried out and parade along Barkhor Street of Lhasa to accept worship of its belivers on the Jan. 17 of every year in lunar calendar. And this is the origin of the religious activity that Tibetan groups in Qiaoqi hold every year by carrying out Maitreya Boddha and going around Qiaoqichang town for a circle to accept worship of the masses. The "Buddha carrying" ritual is to carry out the statue of the Buddha from Yongshou Temple ${ }^{2}$ in Qiaoqi Town. The main belief of Tibetans here is Lamaism. Every year, Lamaism may concentrate in Yongshou Temple to chant scriptures for three times. Wherein, on Jan.17 in lunar calendar, it is to chant the Book of Buddha. Buddhism activity on this day is the grandest activity during the "Buddha Festival".

On this day, people dressed in festive costumes, firstly gathered in Yongshou Temple to pray for peace and good fortune. At about the time of 9:00 am to 11:00 am, under the instruction of Lama, the Tibetan young men whose parents

\footnotetext{
2 Yongshou Temple believes in Qiaoqi's Tibetan Buddhism (also called Lamaism). Emerging of Lamaism in Qiaoqi appeared in Ming Dynasty for the earliest time according to historical record.
}

were alive may carry out the Future Buddha "BYAMS-PA" from Yongshou Temple ${ }^{3}$, with their shoulder carried out scriptures, going slowly down along the stone ladder from Longshengang, and going to the town to accept the worship of each household and then return to Yongshou Temple.

The process of carrying the Buddha is as follows:

1) Before beginning of the ritual (at about 9:00 9:30): In Yongshou Temple, Tibetans dressed in costumes, entering into Yongshou Temple, worshiping Buddha in the temple, burning incense, piously praying for peace and good fortune; then, the Tibetans walk around Yongshou Temple while sing "Mani".

2) In the process of the ritual (at about 9:30 12:00):

- In Yongshou Temple, the Tibetan young men whose parents were alive will successively carry out scriptures. And behind the scriptures, there will be four persons carrying the "Buddha" out of the scripture hall. Then, musicians will blow up tubas and trumpets. At the same time, there will be sounds of firecrackers and cymbals crashing sound.

- In Yongshou Temple, there are five Lamas stood in a row with hand holding scriptures, also four Tibetans looking at a scripture (it is said that these scriptures were brought back from Tibet) and an older Lama seated beside a small table. On the table, there are 12 butter lamps, symbolizing the 12 months. Tibetans carried the scriptures stand neatly in a row, with left shoulder carrying the scriptures and right hand holding a stick of incense.

- On the way from Yongshou Temple to the old town, there will be four Tibetan young men carried the Buddha, followed by the Tibetans next to it. The Tibetans continually sing the polyphonic "Mani". The road down from the mountain was far away and the team was also very long, with their songs sounding one after another.

- In the old town, each household will place offerings in front of the door and light up the incense stick to accept the blessing of the Buddha.

- After going around the old town for a circle and sending the Buddha and scriptures back to Yongshou Temple, this religious activity is over.

As the local lama said, the religious form of "Buddha carrying" was learnt from Tibet, but the "Mani" in this religious activity is unique in the local place. In Tibetan Buddhism, "Mani" is also known as the "six-character mantra". The content is the six-character mantra of Tibetan Buddhism "O-Ma-Ni-Pa-Mi-Ho" (i.e., "Mani" in short). This song is chanted by believers in worshiping in temple in festivals, temple fairs or in normal times. Most of the content chanted is for blessing and relief. In the "Buddha carrying" ritual of the Tibetan groups in Qiaoqi, the polyphonic sing of

\footnotetext{
Future Buddha, also called Maitreya or Eastern Buddha (callued "Qiangba" in Tibetan), is the Buddha dominates the future world in Buddhism.
} 
"Mani" basically spreads all over the ritual. The lyrics are virtual words, have no practical meaning and just express the respect for gods and pray for blessing. It is not difficult to see that the Tibetans here not only transplanted Tibetan religious forms into their culture but also combined their own cultural characteristics.
"Mani", based on a main melody, is often begun singing after a leading singing of one person. Then, the number of persons joining in the singing will be increased gradually from one person to two persons and then to several persons and finally form into a layered polyphonic cantata, as shown in "Fig. 1".

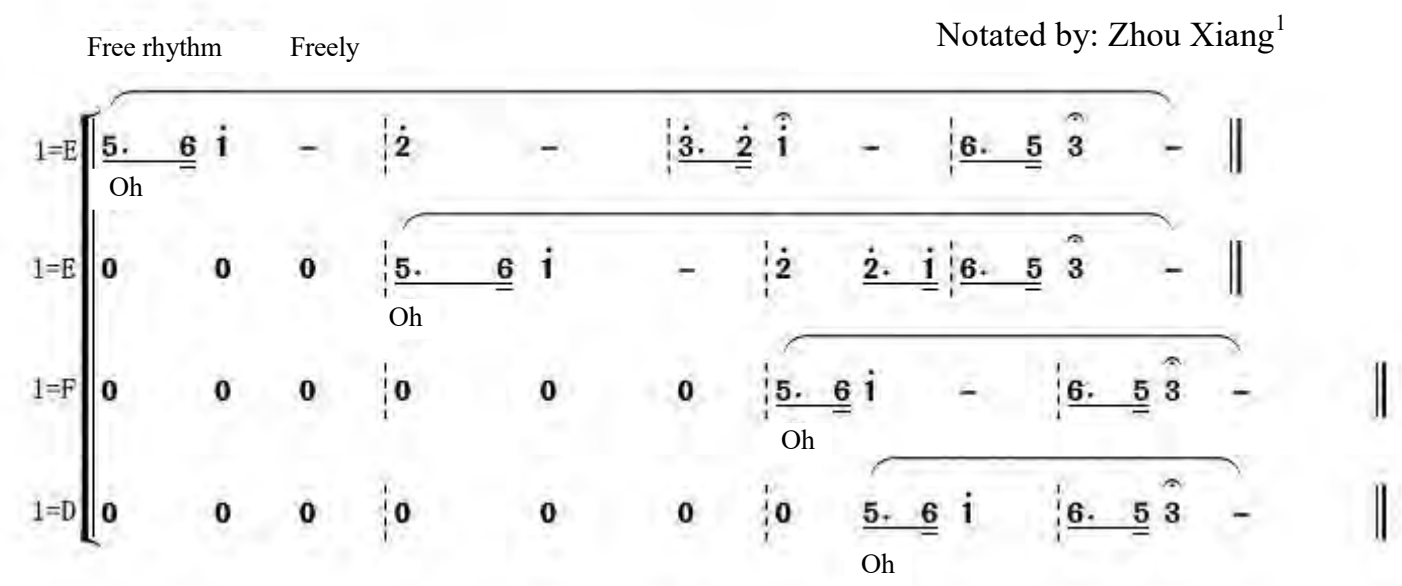

Fig. 1. 1 person $\rightarrow 2$ persons $\rightarrow$ several persons $\rightarrow$ a number of persons $\rightarrow$ forming into a polyphonic cantata.

\section{B. Characteristics of Pitch}

"Mani" is generally sung by a male voice firstly and then followed by the female voice. Female voice often follows after male voice to form a mixed singing effect. In the process of polyphonic singing, male and female don't sing at the same layer due to the male and female's difference in pitch. And the cantata is not set up with a fixed pitch so that individuals can select suitable pitch to sing based on their own voice condition. For example when the attacker sings a melody with pitch equivalent to $\mathrm{E}$, the followed singer may sing this melody at a pitch at least two degrees or two degrees higher than $\mathrm{E}$ if the singer's state or voice condition is good enough; Otherwise, the singer may sing the main melody at a pitch at least two degrees lower than E.

\section{Harmony in Mixed Singing}

The characteristic of "Mani" in Qiaoqi's polyphonic part not only contains the "mixed singing" germination in primitive stage, but also lies in its primary polyphonic consciousness and regularity. This way of mixed singing belongs to simulated ensemble or chorus. On the fixed

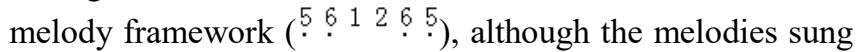
are in various pitches, both male and female voices are unified under the fixed melody rhythm, conducting a simple additions and subtractions. A well-arranged mixed singing effect and harmonious singing is formed under the coordination of the relatively consistent tone and vocal flow of Tibetans and in combination with the relatively fixed beats and fixed beginning and ending melodies.

The three polyphonic forms of Tibetans in Qiaoqi have their own characteristics. The polyphony singing in three different occasions has the same characteristics to some extent. But they also demonstrate different characteristics such as being belief oriented and common customs oriented due to their different functions in different occasions, as shown in "Fig. 2".

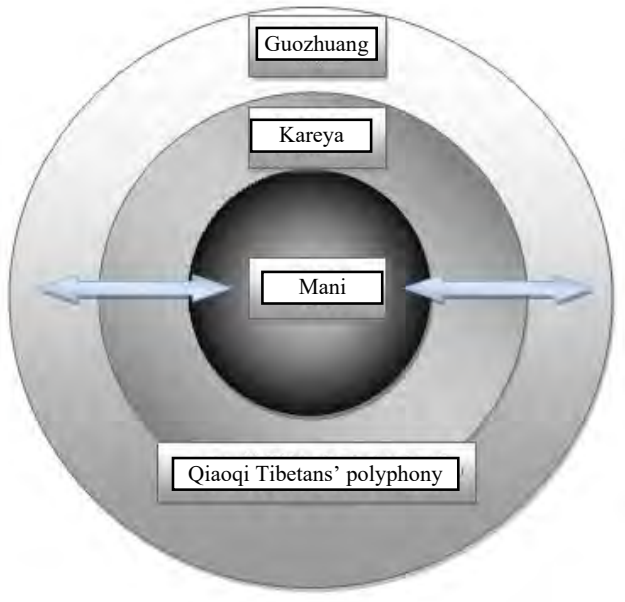

Fig. 2. Belief oriented $\rightarrow$ common customs oriented.

The polyphony of Tibetans here takes "Mani" in the "Buddha carrying" ritual as its core layer, "Kareya" sing and dance as the medium layer and Guozhuang sing and dance as the surface layer which is also the externalized form of polyphony. It is not hard to see that such polyphony fully maintains religion as its core and gradually expands outward. "Mani" at the center level preserves the polyphonic form of the primitive mixed singing; the "Kareya" in medium layer 
has some rituality although it is applied in working and the polyphonic form is gradually transited from mixed singing to simple two-part song. Guozhuang in the outer layer is closely related to daily life entertainment the most, mainly reflecting the polyphonic characteristics in case of there is alternation between two parts. The differences in the three polyphonic forms are expressed in the following "Table I":

TABLE I. DifFERENCE IN THREe POLYPHONIC Forms

\begin{tabular}{|l|l|l|l|}
\hline & \multicolumn{1}{|c|}{ Mani } & \multicolumn{1}{|c|}{$\begin{array}{l}\text { Wheat } \\
\text { harvest-like } \\
\text { dance }\end{array}$} & \multicolumn{1}{|c|}{ Guozhuang } \\
\hline Occassion & $\begin{array}{l}\text { Religious } \\
\text { ritual }\end{array}$ & $\begin{array}{l}\text { Production } \\
\text { work }\end{array}$ & $\begin{array}{l}\text { Life } \\
\text { entertainment }\end{array}$ \\
\hline Part & $4-5$ & 2 & 2 \\
\hline $\begin{array}{l}\text { Polyphonic } \\
\text { form }\end{array}$ & $\begin{array}{l}\text { Mixed } \\
\text { singing }\end{array}$ & Two-part & Two-part \\
\hline Singing form & $\begin{array}{l}\text { One leading } \\
\text { and others } \\
\text { echoing }\end{array}$ & $\begin{array}{l}\text { Antiphonal } \\
\text { singing }\end{array}$ & $\begin{array}{l}\text { Antiphonal } \\
\text { singing }\end{array}$ \\
\hline
\end{tabular}

\section{CULTURAL INTERPRETATION ON TIBETANS' POLYPHONY IN QIAOQI}

Cultural value refers to the special nature of objective things that can satisfy certain cultural needs or the attributes of objective things that can reflect certain cultural forms ${ }^{4}$. Detailed cultural interpretation is formed over an analysis on the cultural value of an objective thing. In the next, the cultural value of polyphony in Qiaoqi will be analyzed in detauked aspect of the "harmonious concept" embodied in Tibetans' polyphony in Qiaoqi.

In Tibetans' polyphony in Qiaoqi, it is integrated with diversified local faith cultures and the multi-layer harmony in comprehensive music and finally forms into its unique "harmonious (music) concept".

\section{A. Harmonious Multi-layer Religious Beliefs}

Qiaoqi Tibetan autonomous town is a diversified religious region co-existing institutional religion and folk beliefs $^{5}$. In the local place, Tibetan Buddhism plays a leading role, folk beliefs of heavy bonism phenomenon take the second place and other folk beliefs dominated by beliefs of god of mountain takes the last place. Such three levels of beliefs all represent human beings' yearn for harmony among the upper, middle and lower level of the world, aiming to pursue a harmonious and stable order in each level and mutual inclusion and co-existing in the special region of Qiaoqi.

Such three levels of beliefs penetrate through polyphonic musics of Qiaoqi. The "Buddha carrying" ritual is an important ritual of Tibetan Buddhism. While the "Mani" sung by Tibetans in the ritual is also a core reflection of Qiaoqi's polyphonic characteristics. Such three levels of beliefs of

\footnotetext{
4 Cai Ling. Literary value of Fujiang's work song. Notonly Music. No.4, 2012. (in Chinese)

Gazang Zhuoma. The influence of diversified religious beliefs on ethnic relationships - taking the Tibetans town of Qiaoqi in Ya'an, Sichuan. Gansu Social Sciences. No.6, 2013. (in Chinese)
}

Tibetans in Qiaoqi not only harmoniously exist in daily life of villagers here but also illustrate a trend of diversified coexisting and harmonious development in polyphony. It also becomes a folk foundation for preserving polyphony.

\section{B. Harmonious Social View}

Polyphony is a music created and played collectively by people of Qiaoqi. Therefore, Qiaoqi's polyphony is a collective music activity. "Joint participation" is one of the key factors no matter in "Mani", "Kareya" or "Qiaoqizhuo". Qiaoqi Tibetans always live in a closed geographical environment, having less communication to the outside world. Hence, social members are needed to jointly take part in no matter working, entertainment and ritual activities. The collective activity mode demonstrates the harmony between Qiaoqi people and the nature and the harmony among people in the society of Qiaoqi. This coordination and uniformity in "fusion of heaven and human beings" right interprets the national cohesion symbol and harmonious beauty demonstrated by the Tibetan groups here.

\section{Harmonious Polyphony.}

The following takes Mani — harmony in mix singing as an example.

1) Harmony in part: Polyphony of Tibetan groups in Qiaoqi is a form of mixed singing. In time of playing "Mani", there may be up to $4 \sim 5$ parts. Each part of "Mani" has the same melody. Although many persons sing, Tibetans here naturally adopts successive entering mode in a tacit understanding. In the process of singing multiple parts, they may appropriately select/abandon the main melody so that the lengths of songs they sing are basically the same. The ending part is uniformly ended in an elongated voice to reach the unification in parts.

2) Harmony in voice: Polyphony of Tibetan groups in Qiaoqi has certain difference in voices due to individual physiological conditions of different singers such as tone, rangeand breath. But Qiaoqi people finally form into a harmonious voice based on the difference. In the "Mani" singing by Qiaoqi people, hundreds of persons can take part in it. However, Tibetans here may select the part suitable for their voice from the differences to realize a harmony and uniformity in sound.

Mixed singing is Tibetans' polyphonic form in Qiaoqi. From the initially unconscious singing to formation of conscious singing, mixed singing embodies Qiaoqi people's cognition of music and beauty. Their uniformity in parts and coordination in voices demonstrates the pursuing for harmony of Qiaoqi people and the beauty of harmony between Qiaoqi people and the society.

The polyphonic culture of Qiaoqi Town shows the beauty of harmony between Qiaoqi people and the society and nature and that among people. This concept is not only embodied in the life and working of Qiaoqi people but also included in the beliefs of Tibetans in Qiaoqi. 


\section{CONCLUSION}

The formation and development of Tibetan' polyphony in Qiaoqi closely depends on its specific ecological environment, production work, religious beliefs and people's concepts and institutions. Those factors is not only the physical and mental foundations for surviving and development of polyphony but also the key contents that it embodied and the true image of such factors. Living on this un-rich land of Qiaoqi, it is inevitable for Tibetans to adapt to it and actively respond to the natural environment and develop and utilize it, thus creating a unique polyphonic culture.

In the Qiaoqi, everyone can sing and dance so that the town is also known as the "town of song and dance." However, the music or dance here is not a demonstration of skills but a collective activity in which everyone can participate. The generation of polyphony also verifies this musical concept. The polyphonic culture expresses the concept of harmonious beauty conveyed by the Tibetan groups in Qiaoqi, the harmony between man and nature, the harmony between man and society as well as the harmony between people and people. This concept is reflected in their production, living and belief, showing the ethnic cohesion of Tibetans in Qiaoqi. Over many years of spreading and singing and depositing, this music has become the most authentic and pure expression of their emotions.

\section{REFERENCES}

[1] County annals of Baoxing edited by local chronicle compilation committee of Baoxing County, Sichuan Province [G]. Fangzhi Publishing House, 2000 (in Chinese). (in Chinese)

[2] Chinese people's political consultative conference and literature and history materials committee of Sichuan Baoxing County Committee. Baoxing literature and history materials, 3rd edition[M]. Ya'an District, Sichuan Province: Sichuan Ya'an Regional Printing House, 1992. (in Chinese)

[3] Geng Junjie, Wang Jie. Brief history of Ya'an [M]. Sichuan University Press, 2010. (in Chinese)

[4] Cao Hong (chief editor). Local chronicle office of Ya'an region. Physical geographic chronicle in Ya'an region [M]. 2000. (in Chinese)

[5] Yao Xiaoxia. Blowing up the tuba [M]. Sichuan Musician's Association and Sichuan Social Music Society, 2006. (in Chinese)

[6] Chinese people's political consultative conference and literature and history materials committee of Sichuan Baoxing County Committee. Baoxing literature and history materials, 3rd edition [M]. Ya'an District, Sichuan Province: Sichuan Ya'an Regional Printing House, 1992. (in Chinese)

[7] "Four-culture" compilation committee of Baoxing County. The romantic town at the foot of Jiajinshan Mountain - cultural Baoxing [M]. China Railway Publishing House, 2004. (in Chinese)

[8] Compilation committee of of Chinese dance chronicle. Chinese dance chronicle - Sichuan $[\mathrm{M}]$. www.xlcbs.com.cn, Dec., 2007. (in Chinese)

[9] Sichuan literary federation. Collection of Chinese customs Sichuan [M]. Sichuan People's Publishing House, 1999. (in Chinese)

[10] Compilation committee of collection of Chinese Folk literature Ya'an. Collection of Chinese folk songs and ballads - Sichuan Ya'an, 1990. (in Chinese)

[11] Cao Baohua (translator). On art [M]. Beijing: SDX Joint Publishing Company. (in Chinese)
[12] Tang Jialu. The cultural ecology of folk art [M]. Tsinghua University Press, 2006. (in Chinese)

[13] Fan Zuyin. Research of Chinese polyphonic folk song [M]. People's Music Publishing House, 2014. (in Chinese)

[14] Fan Zuyin. Introduction of Chinese polyphonic folk song [M]. People's Music Publishing House, 1994. (in Chinese)

[15] Cao Benye. Thought behavior: research on voices in rituals. Shanghai Conservatory of Music Press, 2008. (in Chinese)

[16] National compilation committee member of the Collection of Chinese folk songs and compilation committee of the Collection of Chinese folk songs - Sichuan. Collection of Chinese folk songs - Sichuan (2nd part) [G]. China ISBN Center. (in Chinese)

[17] Li Xingxing. Li Xingxing's view on Tibetan-Yi Corridor [M]. Beijing. The Ethnic Publishing House, 2008. (in Chinese)

[18] Zou Libo. Brief view on the battle between two chieftains Dongbo Hanhu and Zagu in Ming Dynasty - discussion on the factor of Qiang culture in Qiaoqi and Jiarong's Tibetan culture [J].Journal of Aba Teachers University, 2006 (4). (in Chinese)

[19] Duan Guoyun, Duan Yunong. Protection and development of the Tibetan cultural and natural ecological landscape - investigation report on the town of Tibetan groups in Qiaoqi, Baoxing, Sichuan [J]. Journal of Southwest University for Nationalities. Philosophy and Social Sciences, 2002 (3). (in Chinese)

[20] Yangjie, Lu Ying. Development of festival cultural tourism in Sichuan ethnic region in the vision of tourism anthropology taking the Shangjiu festival in Qiaoqi, Baoxing county as an example [J]. Journal of Sichuan Higher Institute of Cuisine, 2011 (3). (in Chinese)

[21] Yuan Lianbo. Current situation of folk performing arts in SichuanTibet region - taking Lan'an town, Luding county and Qiaoqi town, Baoxing county as an example [J]. Literature and Art Forum, 2011 (11). (in Chinese)

[22] Li Jin. Belief of god of mountain: regional link combined with the society - taking the Tibetans town of Qiaoqi in Baoxing county, Sichuan province as an example [J]. Ethno-national Studies, 2012 (2). (in Chinese)

[23] Chen Yan. Anthropology analysis on the value of religious harmony — taking the Tibetans town of Qiaoqi and Jiarong as a study case [J]. Journal of Northwest University For Nationalities, 2011 (5). (in Chinese)

[24] Chen Dong. The Religion on the Tibetan Border: an Investigation into the Religion of Qiaoqi Tibetan Town in Ya'an [J]. Tibetan Studies, 2008 (2). (in Chinese)

[25] Liu Junbo. The Knowledge System of Rong-ba-qie-li Lyrics of JiaRong Tibetans in Qiaoqi Township [J]. Journal of Tibet Nationalities Institute, 2011 (1). (in Chinese)

[26] Li Jin. Land system and acquisition of house name of Jiarong Tibetans - an investigation on Tibetans town of Qiaoqi in Baoxing county, Ya'an city, Sichuan province [J]. Journal of Southwest University for Nationalities, 2010 (5). (in Chinese)

[27] Zou Libo. Primary investigation on house name of Jiarong Tibetans - taking Gari village in Qiaoqi town, Ya'an city as an example [J]. Journal of Tibetology, 2011 (6). (in Chinese)

[28] Yao Xiaoxia. A brief analysis on Guozhuang in Qiaoji, Corpus of Sichuan ethnic folk studies [J]. Sichuan Musician's Association. Beijing: Popular Culture\& Arts Publishing House, 2008: 567-568. (in Chinese)

[29] Yao Xiaoxia. Primary investigation on Tibetans' folk polyphony in Qiaoqi, Corpus of Sichuan ethnic folk studies [J]. Beijing: Popular Culture\& Arts Publishing House, 2008: 569-572. (in Chinese)

[30] Wang Lei. My view on multi-part thinking in Chinese music [J]. Art and Literature for the Masses, 2011 (19). (in Chinese) 